appropriate under the performed model identification. Therefore, it would be necessary to re-evaluate the considered time series in terms of model identification by the Box \& Jenkins method and apply them again to the time series. I expect a notable change of results.

1 Claassen CA, Carmody T, Stewart SM, Bossarte RM, Larkin GL, Woodward WA, et al. Effect of 11 September 2001 terrorist attacks in the USA on suicide in areas surrounding the crash sites. Br J Psychiatry 2010; 196: 359-64.

2 Rinne H, Specht K. Zeitreihen: Statistische Modellierung, Schätzung und Prognose [Time Series: Statistical Modelling, Estimation, Prognosis]. Vahlen 2002.

3 Box GEP, Jenkins GM. Time Series Analysis: Forecasting and Control. Holden-Day, 1976.

4 Helfenstein U. Box-Jenkins modelling in medical research. Stat Methods Med Res 1996; 5: 3-22.

5 Montgomery DC, Weatherby G. Modeling and forecasting time series using transfer function and intervention methods. AlIE Transactions 1980; 12: 289-307.

6 Box GEP, Tiao GC. Intervention analysis with applications to economic and environmental problems. J Am Stat Assoc 1975; 70: 70-9.

Daniel Medenwald, Institute of Medical Epidemiology, Biostatistics and Informatics, University of Halle-Wittenberg, Halle, Germany. Email: daniel.medenwald@uk-halle.de

doi: 10.1192/bjp.202.6.467

\section{Little evidence for the usefulness of violence risk assessment}

Troquete and colleagues report a cluster randomised trial of the effect of violence risk assessment on future offending. ${ }^{1}$ They found that people in the risk assessment group were non-significantly more likely to re-offend than those in the control group. We welcome this analysis of the practical value of risk assessment. There are now literally thousands of published violence risk assessment studies, most of which claim validity for their risk assessment method on the basis of statistical discrimination between violent and non-violent groups using measures such as the area under the curve (AUC) or other indicators of effect size. ${ }^{2}$ Recent criticism of the AUC as an outcome measure has emerged because it does not reflect the accuracy of predictions in the real world, and even high AUC values are associated with a low positive predictive value (PPV) for rare events. However, the PPV of a risk assessment is only a proxy for the usefulness of a risk assessment. A risk assessment alone is not valuable unless it leads reasonable interventions that can reduce future harm. Therefore, the utility of a risk assessment must ultimately be judged by its ability to contribute to harm reduction. In contrast to the large number of papers about the statistical aspects of risk assessment, there may be as few as four published controlled studies of the ability of risk assessment to reduce harm. ${ }^{2}$

The British Journal of Psychiatry has published two earlier studies of the utility of risk assessment. Abderhalden et al reported a cluster randomised trial of risk assessment among in-patients that found that intervention wards had a reduction in violence. However, interpretation of this study is difficult because the intervention wards had high rates of violence pre-trial and posttrial rates of violence in the experimental and control wards did not differ. ${ }^{3}$ Also in the Journal, van de Sande and colleagues reported a cluster randomised trial that found that risk assessment was associated with a reduction in violence but not seclusion among in-patients. ${ }^{4}$ In the nursing literature, Kling et al reported a study in in-patient settings that found that risk assessment was not helpful in reducing violence. ${ }^{5}$

Risk assessment has become the dominant paradigm in mental health practice, policy and legislation in most high-income countries. It should therefore trouble colleagues who support 'evidence-based practice' to know that there is so little evidence for the effectiveness of risk assessment.

1 Troquete NAC, van den Brink RHS, Beintema $\mathrm{H}$, Mulder T, van Os TWDP, Schoevers RA, et al. Risk assessment and shared care planning in out-patient forensic psychiatry: cluster randomised controlled trial. Br J Psychiatry 2013; 202: 365-71.

2 Wand T. Investigating the evidence for the effectiveness of risk assessment in mental health care. Issues Ment Health Nurs 2012; 33: 2-7.

3 Abderhalden C, Needham I, Dassen T, Halfens R, Haug H-J, Fischer JE. Structured risk assessment and violence in acute psychiatric wards: randomised controlled trial. Br J Psychiatry 2008; 193: 44-50.

4 van de Sande R, Nijman HLI, Noorthoorn EO, Wierdsma Al, Hellendoorn E, van der Staak $C$, et al. Aggression and seclusion on acute psychiatric wards: effect of short-term risk assessment. Br J Psychiatry 2011; 199: 473-8.

5 Kling RN, Yassi A, Smailes E, Lovato CY, Koehoorn M. Evaluation of a violence risk assessment system (the Alert System) for reducing violence in an acute hospital: a before and after study. Int J Nurs Stud 2011: 48: 543-9.

Timothy Wand, Emergency Department, Royal Prince Alfred Hospital

and Sydney Nursing School, University of Sydney, NSW, Australia. Email:

timothy.wand@sswhas.nsw.gov.au; Matthew Large, school of Psychiatry,

University of New South Wales, Randwick, NSW, Australia

doi: 10.1192/bjp.202.6.468

Authors' reply: We agree with Wand \& Large that there currently is very limited support for the use of structured risk assessment instruments as a method for violence prevention. So far only a small number of studies, four including our own, examined this issue. It is troubling that most research efforts seem to focus on the development of new risk assessment instruments and establishing their psychometric properties, rather than on testing the effectiveness of existing instruments. Although identification of predictors and development of instruments are crucial steps in the maturation of both risk assessment and forensic psychiatry, the field needs to move beyond these issues.

The most important risk and protective factors associated with recidivism have by now been established and are agreed on by the research community. There is no disputing the existence of correlations between mental illness, substance misuse, client well-being, quality of life and recidivism. That is why all, or a considerable selection of these factors, are commonly included in risk assessment instruments. ${ }^{1-3}$ It seems it is time to move forward and start investigating the benefits of risk assessment instruments and their contribution to more effective treatment interventions in terms of reduction of criminal and violent behaviour. As we ourselves have experienced, introducing randomised trials in clinical practice is difficult, but it can be done, and is an essential step before implementation can be advocated.

A definitive answer about the contribution of structured risk assessment to violence prevention cannot be given at this time. The first signs are not good. The four available studies find either no significant reduction of violent outcome, or the interpretation of their findings is problematic due to differences between study groups at baseline. Differences in clinical setting of the various studies further complicate the integration of findings. Our own data were collected in a community-based forensic mental health setting. In contrast, the other three studies were completed in acute psychiatric (admission) wards. These two settings service different populations, making comparisons less straightforward. It is too early for a proper systematic review on this subject, but the overall picture is not yet convincingly in favour of changing treatment policies by systematically employing structured risk assessment in clinical care. 
On the other hand, our paper also shows that proper implementation in clinical care depends on personnel and organisational factors that need to be addressed in a coherent and persistent way before meaningful results can be obtained. The implementation of a randomised controlled trial has its particular challenges, but so does changing clinical practice in and of itself. ${ }^{4}$ As researchers, we may sometimes underestimate this gap between scientific evidence and the changes necessary in clinical practice for the implementation of evidence-based interventions. In order to reach the ultimate goal of prevention and to determine whether structured risk assessment may contribute, more studies are needed that assess the results of properly implemented and already established instruments in different forms of forensic care.

\section{Declaration of interest}

H.B., T.M. and T.W.D.P.v.O. are the department heads of the clinics where the RACE study was conducted. The study was financially supported by various sources (the University, participating mental health organisations, and national medical research council).
1 Webster CD, Douglas KS, Eaves D, Hart S. HCR-20: Assessing the Risk of Vloience. Version 2. Simon Fraser University and Forensic Psychiatric Services Commission of British Columbia, 1997.

2 Nicholls TL, Brink J, Desmarais SL, Webster CD, Martin ML. The Short-Term ASsessment of Risk and Treatability (START); a prospectlve validation study In a forensic psychlatric sample. In Essential Writing in Violence Risk Assessment and Management (eds $\mathrm{H}$ Bloom, CO Webster). Centre for Addictions and Mental Health, 2007.

3 de vogel V, de Ruiter C, van Beek D, Mead G. Predictive validity of the SVR-20 and Static-99 in a Dutch sample of treated sex offenders. Law Hum Behav 2004; 28: 235-51.

4 Forsner T, Hansson J. Brommels M, Wistedt AA, Forsell Y. Implementing clinical guidelines in psychiatry: a qualitattwe study of perceived facilitators and barrJers. BMC Psychiatry 2010; 10: 8

Nadine Troquete, Rob Giel Research Center, Unwersity Centre for PSychiatry. Untwersily Medical Centre Growingen, CC/2, PO Box 30.0019700 RB Groninger, The Netherlands. Emall: N.A.C.Troquetequmcg.nl; Rob H. S. van den Brink, Rob Glel Research Center, Universily Metical Center Groningerf; Harry Beintema, Mental Health organisation Lentis and Forensic Psyhialtic Clinic dir 5 . van Mesolog. Gronirgetr; Tamara Mulder, Mental Health Organisatons Drenthe, Assen; Ttus W. D. P. van Os, Mental Health Organisations Eriesłand. Leeuwarden; Robert A. Schoevers, Durk Wiersma, Rob Giel Research Center, U/riversity Medical Center Groningen, The Netherlands

doi: $10.1192 /$ bjp.202.6.468a

\section{advances in psychiatric treatment}

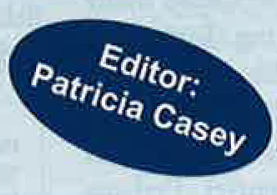

Volume 19, Issue: May 2013 http://apt.repsych.org

\section{CONTENTS}

New from CPD Online

Rethinking placebo in psychiatry: the range of placebo effects

Daniel McQueen, Sarah Cohen, Paul St John-Smith \& Hagen Rampes

Rethinking placebo in psychiatry: how and why placebo effects occur

Daniel McQueen, Sarah Cohen, Paul St John-Smith \& Hagen Rampes

Post-traumatic stress disorder: new directions in pharmacotherapy

Ben Green

Mindfulness-based interventions in secure settings:

challenges and opportunities

Dumindu Witharana \& Gwen Adshead
Refreshment: Managing physical risk in anorexia nervosa

William Rhys Jones, John F. Morgan \& Jon Arcelus

Using psychodynamic principles in formulation in everyday practice

Alison Summers \& Brian Martindale

Recent developments in the management of delusional disorders

Christopher F. Fear

Teamwork: the art of being a leader and a team player Josie Jenkinson, Clare Oakley \& Fiona Mason

Promoting children's resilience to parental mental illness: engaging the child's thinking Alan Cooklin 